2018

\title{
E-Learning Innovations: Implementation of Video in an Occupational Therapy Classroom
}

Amanda K. Giles

Medical University of South Carolina

Dusti Annan

Medical University of South Carolina

Ashlyn Gober

Lisa Greene

Follow this and additional works at: https://encompass.eku.edu/jote

Part of the Occupational Therapy Commons

\section{Recommended Citation}

Giles, A. K., Annan, D., Gober, A., \& Greene, L. (2018). E-Learning Innovations: Implementation of Video in an Occupational Therapy Classroom. Journal of Occupational Therapy Education, 2 (1). https://doi.org/10.26681/jote.2018.020103

This Original Research is brought to you for free and open access by Encompass. It has been accepted for inclusion in Journal of Occupational Therapy Education by an authorized editor of Encompass. For more information, please contact Linda.Sizemore@eku.edu. 


\title{
E-Learning Innovations: Implementation of Video in an Occupational Therapy Classroom
}

\begin{abstract}
Given the growing emphasis on educational technology, it is necessary to inform educators on the best use of video as a course study tool. The aim of this project was to assess the difference between two types of video delivery methods in relation to occupational therapy student satisfaction and usage. Eighty-nine occupational therapy students used one of two types of video delivery methods for learning upper extremity goniometry: short videos embedded within e-learning modules or live lab video recordings available via a learning management system. Qualitative and quantitative data on student perceptions and usage were collected and analyzed. Students with access to e-learning module videos were more satisfied than those with access to live video recordings in terms of preparedness for exams, confidence, and accessibility. All students reported that access to videos was helpful in preparing for labs and exams. To maximize student satisfaction and usage, educators should consider providing short videos via e-learning modules.
\end{abstract}

\section{Keywords}

Educational technology, preparation, instructional methods

\section{Creative Commons License}

\section{(ब) (1) $\Theta$}

This work is licensed under a Creative Commons Attribution-Noncommercial-No Derivative Works 4.0 License.

\section{Acknowledgements}

This research was made possible by funding and resources from the Medical University of South Carolina (MUSC) Department of Health Professions, MUSC Technology Applications Center for Healthful Lifestyles, and the MUSC Office of Instructional Technology and Faculty Resources. We thank the MUSC Occupational Therapy Classes of 2015 and 2016 for their support. 


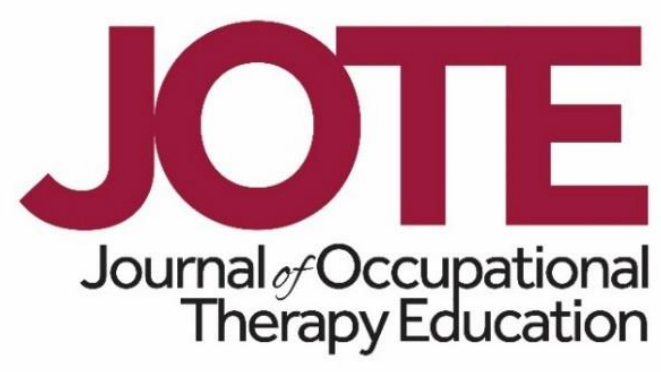

Volume 2, Issue 1

\title{
E-Learning Innovations: Implementation of Video in an Occupational Therapy Classroom
}

\author{
Amanda K. Giles, OTD, OTR/L, Dusti Annan, EdD, \\ Ashlyn Gober, MS, OTR/L, and Lisa Greene, MS, OTR/L \\ Medical University of South Carolina \\ United States
}

\begin{abstract}
Given the growing emphasis on educational technology, it is necessary to inform educators on the best use of video as a course study tool. The aim of this project was to assess the difference between two types of video delivery methods in relation to occupational therapy student satisfaction and usage. Eighty-nine occupational therapy students used one of two types of video delivery methods for learning upper extremity goniometry: short videos embedded within e-learning modules or live lab video recordings available via a learning management system. Qualitative and quantitative data on student perceptions and usage were collected and analyzed. Students with access to e-learning module videos were more satisfied than those with access to live video recordings in terms of preparedness for exams, confidence, and accessibility. All students reported that access to videos was helpful in preparing for labs and exams. To maximize student satisfaction and usage, educators should consider providing short videos via e-learning modules.
\end{abstract}

\section{INTRODUCTION}

Current trends in higher education demand the need to re-examine traditional pedagogical approaches and consider innovative online learning experiences (Chick, Haynie, Gurung, \& Ciccone, 2012). Students have become complacent about taking responsibility for their own learning outside of the classroom, particularly in preparation for class, and instead rely on faculty lecture notes as their primary study tool (Huon, Spehar, Adam, \& Rifkin, 2007). Video is a commonly-utilized educational technology, but there is a lack of literature in higher education regarding the appropriate implementation of video as a course preparatory tool (Evans, 2014). The purpose of this paper is to explore the differences between two types of video delivery methods as they 
relate to occupational therapy student confidence and satisfaction as well as occupational therapy student usage before class versus before an exam.

\section{Student Preparation for Class}

Students are traditionally required to read textbook pages in preparation for class, but studies show that students are not following through with their assigned readings (Starcher \& Proffitt, 2011). In fact, student noncompliance with reading assignments has steadily worsened over time based on a longitudinal study by Burchfield and Sappington (2000). Hoeft (2012) found that students are not reading for a number of reasons, including: (1) students do not find reading to be an efficient use of time, (2) students are not held accountable, (3) students believe readings are too long, and (4) students are not interested in the topic.

When students come to class unprepared, it diminishes the quality of discussion and lessens the amount of time dedicated to critical thinking (McLaughlin et al., 2014). Thus, it is worthwhile for educators to consider ways to motivate class preparation. Studies show that students are more likely to prepare for class when held accountable for learning. For example, students are more likely to read the textbook prior to an exam than prior to class (Clump, Bauer, \& Breadley, 2004). Further, students are more likely to prepare for class when given guided preparation assignments, such as reflection papers and group discussion (Ewell \& Rodgers, 2014).

\section{Student Perceptions of Video as a Learning Tool}

Videos offer a multi-sensory approach to learning that engages students' attention, piques their interest, and helps them to maintain focus during class (Kosterelioglu, 2016). Students value videos as a course study tool, noting specifically convenience, ease of use, and efficiency (Long, Logan, \& Waugh, 2016; Sherer \& Shea, 2011). Students report that online videos are motivating and allow for control over learning, specifically in reference to location and time of learning, content, and pace (Bolliger, Supanakorn, \& Boggs, 2010; Jarvis \& Dickie, 2010; Kay, 2012; Perlman, Weston, \& Gisel, 2010). Videos have been found particularly beneficial when used to conceptualize difficult topics, promote critical reflection, and foster deeper learning (Hund \& Getrich, 2015; Kay, 2012). McAlister (2014) found that occupational therapy students reported increased confidence in manual skills when using video of in-class demonstrations. Overall, students find benefit in and desire the continued use of videos in the classroom (Long et al., 2016; Rudow \& Sounny-Slitine, 2015).

\section{Video Development and Delivery}

The way in which a video is produced and delivered greatly influences whether or not students are satisfied and engaged; video length, presentation style, and quality of video are all critical factors to consider when embedding video into a course (Hong, Zhongling, \& Yang, 2016; Schmid et al., 2014). Educators often record full-length lectures, which results in videos that are long, bulky, and may have technical issues during playback; long video lengths can deter student use and impede learning outcomes (Buzzetto-More, 2014; Hajhashemi, Caltabiano, \& Anderson, 2016; Schmid et al., 2014). While the research data on optimal video length remains largely 
observational, the majority of studies have recommended ranges from 20-30 minutes down to three minutes (Pi \& Hong, 2015; Wilson \& Korn, 2007).

In addition to video length, the presentation style, video quality, and special features should be carefully selected in order to maximize the student response. Students are more engaged when the instructor is present, speaks in a fast, enthusiastic tone, and incorporates a variety of multimedia elements (Hajhashemi et al., 2016). Likewise, poor visual and audio quality can negatively affect student satisfaction (Hajhashemi et al., 2016). Using an interactive component within the video may also increase student engagement and learning outcomes (Stonebraker, Robertshaw, \& Moss, 2016). Efficiency, engagement, and convenience are now anticipated components of the learning process. With recent advances in educational technology, more opportunities exist for educators to create well-organized, interactive videos that motivate self-study (Schols, 2012).

\section{BACKGROUND}

Two different delivery methods for videos on goniometry, the measurement of joint motion, were prepared and utilized as a resource outside of class time: live lab videos and short e-learning module videos.

\section{Live Lab Videos}

Three upper extremity goniometry lab sessions were video-recorded live and made accessible the following year to students prior to lab via Moodle, an online learning management system (https://moodle.org/). Each video was 75 minutes long. Students were encouraged to review the lab videos in conjunction with a traditional goniometry textbook that included photos and text instructions for client position, goniometer placement, precautions, and normal range of motion. For the purpose of this paper, the live lab video recordings will be referred to as lab videos.

\section{E-learning Module Videos}

Approximately 35 short videos (two to three minutes each) on upper extremity goniometry were produced using high-definition professional videography. The videos were embedded within e-learning modules using Articulate Storyline, an e-learning software application (https://articulate.com/ii). The e-learning modules included photos and text instructions for client position, goniometer placement, precautions, normal range of motion, documentation, and goal-writing. Access to the e-learning modules was obtained via a username and password from a web browser. For the purpose of this paper, the videos embedded within e-learning modules will be referred to as module videos.

\section{Theoretical Approach}

This project was largely guided by Mayer's Cognitive Theory of Multimedia Learning, which states that "people learn more deeply from words and pictures than from words alone" (Mayer, 2009, p. 47). The use of video provides both visual and auditory stimuli, 
which have been shown to be more effective when used together than when used in isolation (Shams \& Seitz, 2008).

This project was also influenced by Knowles' Adult Learning Theory, which posits that meaningful learning for adults involves autonomous learning (Knowles, Holton, \& Swanson, 2015). The purpose of the module videos was to allow a clear and organized way in which students could review goniometry methods independently at their own pace outside of lab time and thus reduce dependency on the faculty member.

\section{Purpose of the Study}

The purpose of this study was to explore the style of preparatory materials used for a lab course and its impact on student satisfaction and usage. In particular, live lab recordings (lab videos) were compared to short videos embedded within an interactive e-learning module (module videos).

The following hypotheses were proposed:

Hypothesis 1. Students using module videos will report greater satisfaction compared to students using lab videos.

Hypothesis 2. Students using module videos will report using videos more frequently compared to students using lab videos.

\section{METHODS}

\section{Participants}

Participants of this study included occupational therapy graduate students from the Class of 2015 (CO2015, n=44) and the Class of 2016 (CO2016, n=45) enrolled in a required Occupational Performance for Musculoskeletal Conditions I Laboratory course at the Medical University of South Carolina. Student mean age for the CO2015 was 24 years and ranged from 21-34. Student mean age for the CO2016 was 23 years and ranged from 21-29. Participants were primarily female (89\% for CO2015 and 93\% for CO2016). All participants were United States residents.

\section{Procedures}

C02015. The CO2015 was given access to the live lab video recordings. Students were encouraged to review the lab videos and goniometry textbook prior to lab and practical exam. Following the lab practical exam, a faculty-developed survey was administered to gather information regarding student perceptions.

C02016. The $\mathrm{CO} 2016$ was given access to the e-learning module videos rather than the lab videos. Students were encouraged to review the e-learning modules prior to lab and practical exam. Following the lab practical exam, a faculty-developed survey was administered to gather information regarding student perceptions. 


\section{Data Collection}

Both quantitative and qualitative data were collected and analyzed at the same time in order to gain a deeper understanding of student perceptions and student usage in relation to the two types of video presented.

Student perceptions. Student perceptions of the lab videos and the module videos were gathered using a six-question survey, which included four, five-point Likert scale questions and two open-ended questions. The Likert scale questions were concerned with preparedness, confidence, accessibility and recommendations for further use of video. The two open-ended questions collected perceptions on the benefits of the technology used and recommendations for improvement (Table 1).

Table 1

\section{Survey questions}

\section{LIKERT-SCALE QUESTIONS}

1. Using the goniometry videos helped me prepare for the practical exam.

2. Using the goniometry videos increased my confidence level as an occupational therapy student.

3. I was able to access the goniometry videos easily.

4. I recommend continuation of the goniometry videos in the future.

\section{OPEN-ENDED QUESTIONS}

1. What are the benefits of having access to goniometry videos?

2. What changes would you suggest to improve the current goniometry videos?

Usage. Student usage data was gathered to calculate (1) the amount of time spent using the video and (2) the timing of when students used the technology within the curriculum. The $\mathrm{CO} 2015$ reported usage quantities through an anonymous survey postcourse completion. The CO2016 usage was tracked directly through the Articulate Storyline hosting service.

Informed consent and IRB approval. Each student was informed that participation in this study was voluntary, anonymous, and had no bearing on his/her grade for the course. The study was exempted from human subjects approval by the Medical University of South Carolina Institutional Review Board.

\section{RESULTS}

Surveys were completed by 44 of 44 students in the CO2015 (100\% response rate) and 43 of 45 students in the CO2016 (95\% response rate).

\section{Responses to the Quantitative Survey Questions}

Responses to the first four survey questions were analyzed using four independent ttests assuming equal variances. Students with access to the module videos were significantly more likely to report that video helped them prepare for the exam (95.4\%) 
compared to students with access to the lab videos $(46.7 \%)(p<0.001)$. Students with access to the module videos were significantly more likely to report that using videos increased confidence on the practical exam (95.3\%) compared to students with access to the lab videos $(53.3 \%)(p<0.001)$. Students with access to the module videos were significantly more likely to report that they were more easily able to access the videos (84.4\%) compared to students with access to the lab videos $(53.3 \%)(p<0.001)$.

Students with access to the module videos were significantly more likely to recommend video continuation (100\%) compared to students with access to the lab videos $(82.2 \%)$ $(p<0.001)$ (Figure 1).

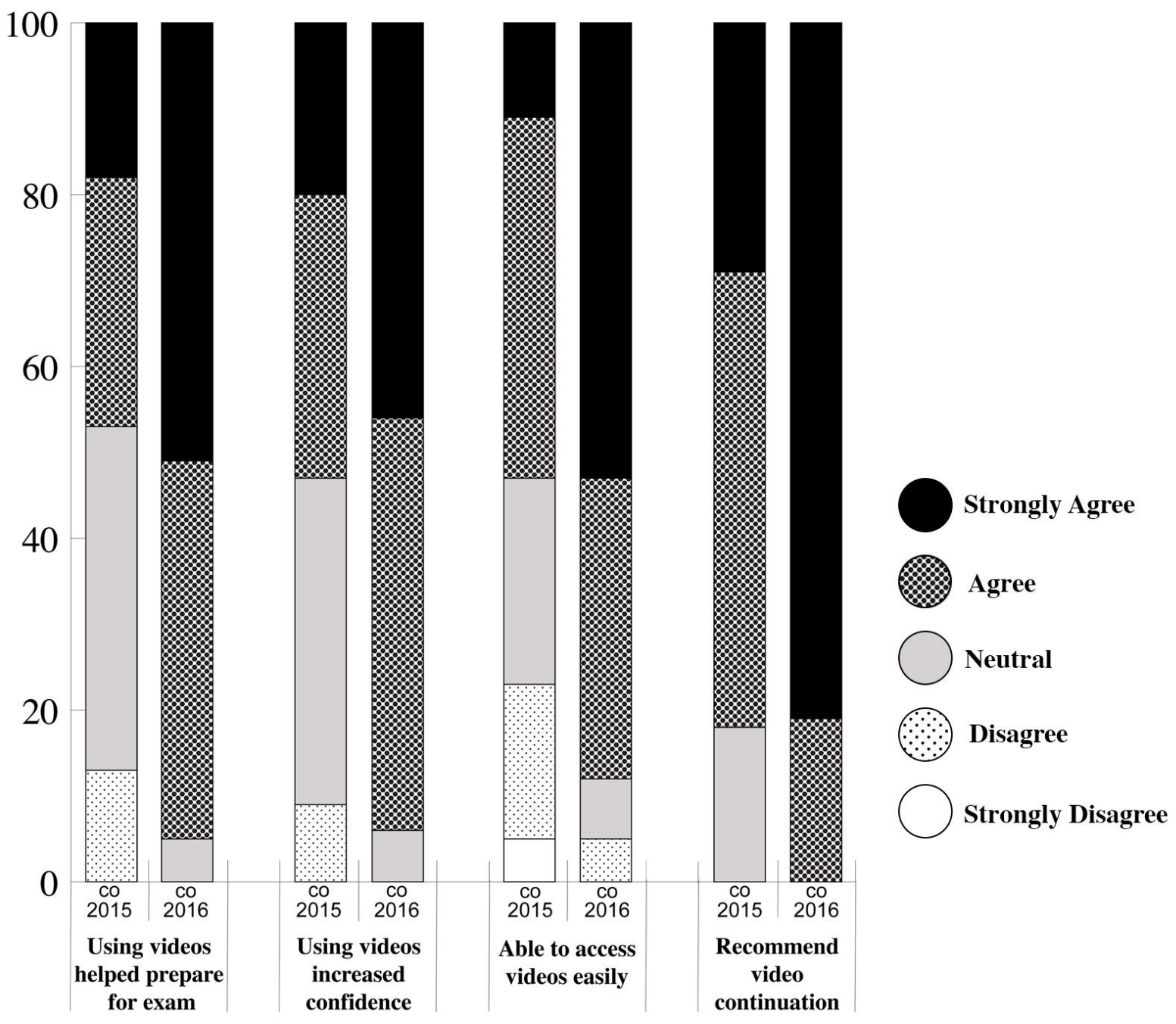

Figure 1. Student responses to quantitative survey questions.

\section{Student Usage}

Data were collected on student usage of video before lab class and before a practical exam. Data were analyzed using descriptive statistics; measures of frequency were compared between the CO2015 and CO2016. For the CO2015, student use of live 
video recordings was greater prior to lab practical exam (43\%) than prior to lab (20\%). For the CO2016, student use of the e-learning modules was greater prior to lab practical exam (62\%) than prior to lab (42\%) (Figure 2).

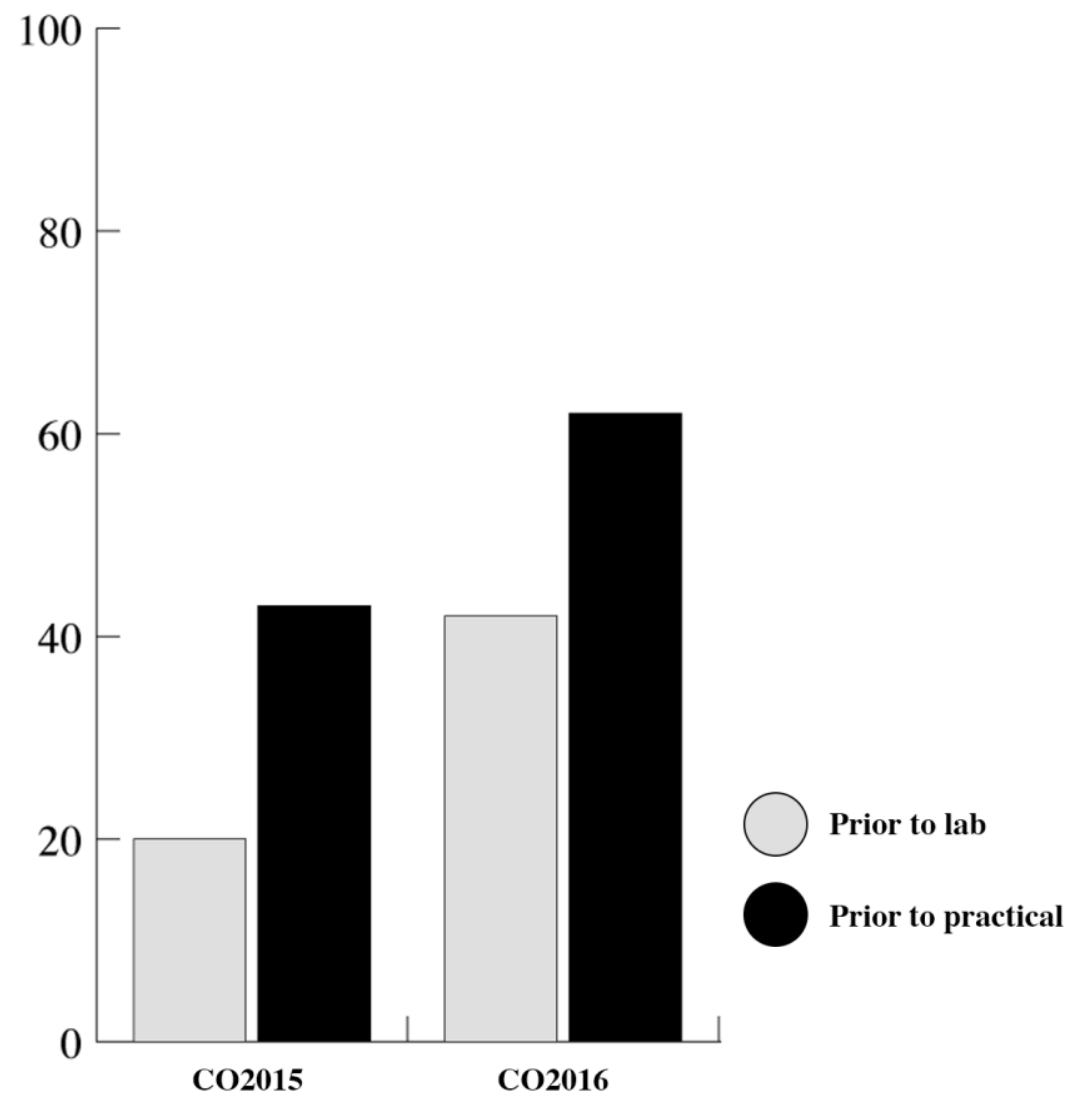

Figure 2. Student usage of video prior to lab and prior to lab practical exam.

\section{Responses to Open-Ended Questions}

Responses to the two open-ended questions were analyzed using thematic content analysis, a commonly used form of qualitative data analysis which detects matters considered by a group of participants to be of the most importance (Green \& Thorogood, 2013). Primary codes and a summary statement for each code were created and linked to student responses in order to create a framework for identifying and organizing recurring themes. The responses of each participant were compared with every other participant. Codes that consistently reappeared were synthesized and grouped into themes. Coding was validated by consensus of two authors (Giles and Gober).

Benefits of lab videos. Two themes emerged from the open-ended question related to the benefits of having access to the lab videos (Table 2). 
Table 2

Benefits of Lab Videos

\section{Lab video demonstrations make content easier to visualize and understand than a traditional textbook.}

- "Being able to picture measurements instead of trying to interpret word descriptions or textbook photos."

- "If you forgot how to measure a particular joint motion, a video is much easier to follow than reading a lot of words. In addition, it is easier to visualize how to do a measurement when you can see it, rather than read about it."

\section{Lab videos can be used to review material at an individualized pace outside of} class.

- "It's nice to have a place to review what was talked about in class, as we only have 2 hours in lab to learn the content. It's especially helpful in preparation for practicals because so much time has passed, as well as more information has been learned in between."

- "You can review videos at your convenience and utilize videos when studying with a partner."

Recommendations for lab videos. Two themes emerged from the open-ended question requesting recommendations for the lab videos (Table 3).

Table 3

Recommendations for Lab Videos

Lab videos need to be shorter and focused on chunks of material.

- "[Lab videos] make it hard to find specific item you're looking for. Maybe if the videos were better broken down into sections that were covered in it."

- "Make the [lab] videos shorter and to the point."

\section{Lab videos should be easy to access and free of technical difficulties.}

- "[Lab] video freezes a lot."

- "Improve the quality [of lab video], sometimes mine would skip or pause or take a long time to load." 
Benefits of module videos. The following three themes emerged from the open-ended question related to the benefits of having access to the module videos. The first two themes are the same themes as found in the responses from students using lab videos (Table 4).

Table 4

Benefits of Module Videos

\section{Module video demonstrations make content easier to visualize and understand than a traditional textbook. \\ - "You can repeat as necessary and get a visual image that explains more than the book ever could." \\ - "It is easier to understand and learn goniometry when seeing it done than by reading about it. It's also helpful to be able to re-watch the video multiple times when there is confusion as opposed to seeing it done once in lab."}

\section{Module videos can be used to review material at an individualized pace outside} of class.

- "Access to the videos allows for students to clarify, review, or learn techniques that can't be shown otherwise outside of the lab setting."

- "We can watch them at any time and repeat them as needed so we can learn at our own speed."

\section{Module videos are organized, short, and focused on chunks of material.}

- "[Module videos] give a clear and concise way to measure UE ROM."

- "The materials are laid out clearly in the same format for each joint so it is easy to follow and study from."

Recommendations for module videos. The final theme emerged from the openended question related to recommendations for the module videos (Table 5).

Table 5

Recommendations for Module Videos

\section{Module videos should be easy to access and free of technical difficulties.}

- "I have been accessing the [module] videos via a video link in my email. Having a direct website to log in to would make watching the videos easier and more convenient."

- "Access was a bit limited [with module videos] because my internet connection at home is slow. It would be great if there could be a way to download them without using internet." 


\section{DISCUSSION}

Innovations in technology have changed the landscape of what students expect and desire from learning experiences. This article compared two delivery methods of preparatory videos used within an occupational therapy lab classroom: (1) traditional, live lab video recordings and (2) short videos embedded within interactive e-learning modules. Survey data was collected and analyzed regarding student preferences and usage.

Occupational therapy student feedback mirrored current research in educational technology. Specifically, students favor instruction that is supplemented with multimedia (Hajhashemi et al., 2016). Students reported that visual demonstration of motor skills necessary for goniometry made the information easier to learn and practice than pictures and text alone regardless of the delivery method. The ability to re-watch the videos allowed for studying to be completed at the students' pace outside of the designated lab time and offered clarification for difficult concepts and forgotten steps.

While both groups of students appeared to value video as an educational tool, student perceptions were significantly more positive for the group with access to the module videos. Students using the module videos were more likely to recommend the continued use of videos in future classes. Further, students with access to the module videos reported greater confidence and greater readiness for the practical examination when compared to those with access to the lab videos. Based on the qualitative student feedback, this is likely explained by the shortened length of video and the interactive nature of the e-learning modules. Students may also have preferred the module videos because they were less likely to exhibit technical difficulties than the live lab videos. These results highlight the fundamental impact of video length, accessibility, and interactivity on the success of video as an educational modality.

A difference in student usage was also noted between the two delivery methods. Students who had access to module videos were more likely to use the videos in preparation for lab and exam than the students who had access to the lab videos. All students were more likely to view videos prior to an exam versus prior to lab. It is assumed that the academic weight of an exam holds students more accountable to reviewing videos prior to an exam versus prior to lab; results may have been different if students had been held accountable to preparing for lab by use of a pre-lab quiz. Student usage in general was lower than expected, which may be due to issues of accessibility experienced by both groups and/or lack of accountability prior to lab.

\section{Implications for Occupational Therapy Educators}

The role of the educator is to prepare the occupational therapy student for clinical practice using the most up-to-date, evidence-based teaching tools available. Students want learning tools that are convenient, accessible, and visually appealing (Long et al., 2016). Video is a useful tool to meet this need when used appropriately. 
To increase student satisfaction with learning and student use of video in preparation for class, the following recommendations are offered to educators based on student feedback:

- Consider unique ways to utilize videos as preparation tools, particularly for lab skills.

- Keep videos concise and to the point by avoiding unnecessary details.

- Ensure that the video delivery method is free of technical difficulty.

- Use a video delivery method that makes videos easily accessible.

\section{Limitations}

The following limitations should be noted. (1) Data was drawn from a convenience sample of students. (2) Usage data was gathered directly from the hosting platform for the e-learning module videos, but relied on student self-report for the live video recordings. Self-report is inherently less reliable than direct monitoring of use.

\section{Directions for Future Research}

As technology continues to expand and improve, educators must consider new and unique ways in which video can add value to the classroom using an evidence-based approach. Future research should consider: (1) the effect of video on learning retention, (2) the effect of holding students accountable for lab preparation, and (3) student perceptions on the accessibility of alternative delivery methods, such as mobile applications. Use of standardized surveys, such as the Mobile App Rating Scale (MARS), for student perceptions of educational technology should also be considered (Stoyanov et al., 2015).

\section{References}

Bolliger, D.U., Supanakorn, S., \& Boggs, C. (2010). Impact of podcasting on student motivation in the online learning environment. Computers \& Education, 55(2), 714-722. https://doi.org/10.1016/j.compedu.2010.03.004

Burchfield, C. M., \& Sappington, J. (2000). Compliance with required reading assignments. Teaching of Psychology, 27(1), 58-60. Retrieved from http://files.eric.ed.gov/fulltext/EJ854930.pdf

Buzzetto-More, N. A. (2014). An examination of undergraduate student's perceptions and predilections of the use of YouTube in the teaching and learning process. Interdisciplinary Journal of E-Learning and Learning Objectives, 10, 17-32. https://doi.org/10.28945/1965

Chick, L., Haynie, A., Gurung, R., \& Ciccone, A. (2012). Exploring more signature pedagogies: Approaches to teaching disciplinary habits of mind. Sterling, VA: Stylus Publishing, LLC.

Clump, M. A., Bauer, H., \& Breadley, C. (2004). The extent to which psychology students read textbooks: A multiple class analysis of reading across the psychology curriculum. Journal of Instructional Psychology, 31(3), 227-232. Retrieved from https://eric.ed.gov/?id=EJ774105

Evans, H. K. (2014). An experimental investigation of videotaped lectures in online courses. TechTrends, 53(3), 63-70. https://doi:10.1007/s11528-014-0753-6 
Ewell, W. H., \& Rodgers, R. R. (2014). Enhancing student preparedness for class through course preparation assignments: Preliminary evidence from the classroom. Journal of Political Science Education, 10, 204-221. https://doi:10.1080/15512169.2014.893760

Green, J., \& Thorogood, N. (2013). Qualitative methods for health research (3 ${ }^{\text {rd }}$ ed.). London: Sage.

Hajhashemi, K., Caltabiano, N., \& Anderson, N. (2016). Students' perceptions and experiences towards the educational value of online videos. Australian Educational Computing, 31(2), 1-17. Retrieved from http://journal.acce.edu.au/index.php/AEC/article/view/115

Hoeft, M. E. (2012). Why university students don't read: What professors can do to increase compliance. International Journal for the Scholarship of Teaching and Learning, 6(2), Article 12. https://doi:10.20429/ijsotl.2012.060212

Hong, J., Zhongling, P., \& Yang, J. (2016). Learning declarative and procedural knowledge via video lectures: Cognitive load and learning effectiveness. Innovation in Education and Teaching International, 0, 1-8. https://doi:10.1080/14703297.2016.1237371

Hund, L., \& Getrich, C. (2015). A pilot study of short computing video tutorials in a graduate public health biostatistics course. Journal of Statistics Education, 23(2), 1-16. https://doi.org/10.1080/10691898.2015.11889736

Huon, G., Spehar, B., Adam, P., \& Rifkin, W. (2007). Resource use and academic performance among first year psychology students. Higher Education, 53, 1-27. https://doi:10.1007/s10734-005-1727-6

Jarvis, C., \& Dickie, J. (2010). Podcasts in support of experiential field learning. Journal of Geography in Higher Education, 34(2), 173-186. https://doi:10.1080/0398260903093653

Kay, R. H. (2012). Exploring the use of video podcasts in education: A comprehensive review of the literature. Computers in Human Behavior, 28, 820-831. https://doi:10.1016/j.chb.2012.01.011

Knowles, M. S., Holton III, E. F., \& Swanson, R. A. (2015). The adult learner: The definitive classic in adult education and human resource development $\left(8^{\text {th }}\right.$ ed.). London, England: Routledge.

Kosterelioglu, I. (2016). Student views on learning environments enriched by video clips. Universal Journal of Educational Research, 4(2), 359-369. https://doi:10.13189/ujer.2016.040207

Long, T., Logan, J., \& Waugh, M. (2016). Students' perceptions of the value of using videos as a pre-class learning experience in the flipped classroom. Tech Trends, 60, 245-252. https://doi:10.1007/s11528-016-0045-4

Mayer, R. E. (2009). Multimedia learning. Cambridge: Cambridge University Press. https://doi.org/10.1017/CBO9780511811678

McAlister, R. B. (2014). Use of instructor-produced YouTube ${ }^{\circledR}$ videos to supplement manual skills training in occupational therapy education. American Journal of Occupational Therapy, 68(2), S67-S72. https://doi:10.5014/ajot.2014.685S04 
McLaughlin, J. E., Roth, M. T., Glatt, D. M., Gharkholonarehe, N., Davidson, C. A., Griffin, L. M., Esserman, D. A., \& Mumper, R. J. (2014). The flipped classroom: A course redesign to foster learning and engagement in a health professions school. Academic Medicine, 89(2), 236-243. https://doi.org/10.1097/ACM.0000000000000086

Perlman, R., Weston, C., \& Gisel, E. (2010). Enabling meaningful learning through Web-based instruction with occupational therapy students. Educational Technology Research and Development, 58, 191-210. https://doi:10.1007/s11423-008-9097-2

$\mathrm{Pi}, \mathrm{Z}$., \& Hong, J. (2015). Learning process and learning outcomes of video podcasts including the instructor and PPT slides: A Chinese case. Innovations in Education and Teaching International, 53(2), 135-144. https://doi:10.1080/14703297.2015.1060133

Rudow, J. \& Sounny-Slitine, M. A. (2015). The use of web-based video for instruction of GIS and other digital geographic methods. Journal of Geography, 114(4), 168175. https://doi:10.1080/00221341.2014.977932

Schmid, R. F., Bernard, R. M., Borokhovski, E., Tamim, R. M., Abrami, P. C., Surkes, M. A., Wade, A. C., \& Woods, J. (2014). The effects of technology use in postsecondary education: A meta-analysis of classroom applications. Computers \& Education, 72, 271-291. https://doi:10.1016/i.compedu.2013.11002

Schols, M. (2012). Examining and understanding transformative learning to foster professional technology development in higher education. International Journal of Emerging Technologies in Learning, 7, 41-49. https://doi:10.3991/ijet.v7il.1764

Shams, L., \& Seitz, A. R. (2008). Benefits of multisensory learning. Trends in Cognitive Sciences, 12(11), 411-417. https://doi:10.1016/j.tics.2008.07.006

Sherer, P., \& Shea, T. (2011). Using online video to support student learning and engagement. College Teaching, 59(2), 56-59.

https://doi.org/10.1080/87567555.2010.511313

Starcher, K., \& Proffitt, D. (2011). Encouraging students to read: What professors are (and aren't) doing about it. International Journal of Teaching and Learning in Higher Education, 23(3), 396-407. Retrieved from https://eric.ed.gov/?id=EJ946166

Stonebraker, I., Robertshaw, M. B., \& Moss, J. D. (2016). Student see versus student do: A comparative study of two online tutorials. TechTrends: Linking Research and Practice to Improve Learning, 60(2), 176-182. https://doi:10.1007/s11528016-0026-7

Stoyanov, S. R., Hides, L., Kavanagh, D. J., Zelenko, O., Tjondronegoro, D., \& Mani, M. (2015). Mobile app rating scale: A new tool assessing the quality of health mobile apps. Journal of Medical Internet Research, 3(1), e27. https://doi:10.2196/mhealth.3422

Wilson, K., \& Korn, J. H. (2007). Attention during lectures: Beyond ten minutes. Teaching of Psychology, 34(2), 85-89. https://doi.org/10.1177/009862830703400202 